\title{
Reflexões sobre dança na educação física escolar
}

\author{
Reflections about dance in scholar physical education \\ Reflexiones sobre la danza en la educación física escolar \\ Flávio Soares Alves ${ }^{1}$; Yara Aparecida Couto ${ }^{2}$ \\ Universidade Estadual Paulista "Júlio de Mesquita Filho", UNESP, Rio Claro-SP, Brasil \\ Universidade Federal de São Carlos, UFSCAR, São Carlos-SP, BraSIL
}

\begin{abstract}
RESUMO
Esse ensaio debate alguns desacertos envolvendo a dança na Educação Física Escolar. Para tanto, parte de uma experiência didática envolvendo o ensino das danças no contexto do Mestrado Profissional (ProEF). Neste contexto de partida, recolocam-se questões acerca da dimensão educativa atribuída à dança na escola, o que exige a busca de compreensões mais amplas acerca da dança - aqui instaladas a partir do enfoque da Dança Criativa e dos estudos Labanianos - bem como, a afirmação de uma aposta - aqui apoiada na dança da cultura Hip-hop - que, enquanto tal, oportunize sempre de modo reflexivo, crítico e situado, a mobilização de maiores relações de sentido no encontro entre estudantes, a dança e a Educação Física Escolar.
\end{abstract}

Palavras-chave: Ensino. Dança. Mestrado Profissional. Educação Física Escolar.

\begin{abstract}
This essay debates some mistakes involving dance in the Scholar Physical Education. For this, it starts from a didactic experience involving the teaching of dances in the Professional Master's context (ProEF). In this context of departure, questions are raised about the education dimension attributed to dance at school, which requires the search for broader understandings about dance - installed here from the Creative Dance focus and Labanian studies - as well as the affirmation of a bet - supported here in the dance of Hip-hop culture - that, as such, makes possible in a reflective, critical and situated way, to the mobilization of greater relations of meaning in the meeting between students, dance and Scholar Physical Education.
\end{abstract}

Keywords: Teaching. Dance. Professional Master. Scholar Physical Education.

\section{RESUMEN}

Este ensayo debate sobre algunos desaciertos relacionados com la danza en la Educación Física Escolar. Para tanto, se parte de uma experiencia didáctica que implica la enseñanza de danzas en el contexto del Máster Profesional (ProEF). En este contexto de partida, se plantean interrogantes sobre la dimensión educativa atribuída a la danza en la escuela, que requiere la búsqueda: de entendimientos más amplios sobre la danza instalados aqui desde el enfoque de la Danza Creativa y los estudios Labanianos - así como la afirmación de uma apuesta - apoyada aqui en la danza de la cultura Hip-hop - que, como tal, aprovecha siempre de manera reflexiva, crítica y situada, la movilización de mayores relaciones de sentido en el encuentro entre los estudiantes, la danza y la Educación Física Escolar.

Palabras clave: Enseñanza. Danza. Máster Profesional. Educación Física Escolar.

\footnotetext{
${ }^{1}$ Professor Assistente do Departamento de Educação Física da UNESP Rio Claro. Pesquisador e co-criador do Grupo "E-LABORE(si) - práticas corporais e tecnologias" (UNESP Rio Claro). E-mail: flavio.alves@unesp.br. ORCID: http://orcid.org/0000-0002-1698-6535.

2 Professora Associada do Departamento de Educação Física e Motricidade Humana da UFSCar. E-mail: yaracouto@ufscar.br. ORCID: http://orcid.org/0000-0003-1851-4889.
} 


\section{UM LUGAR DE FALA}

As reflexões observadas neste texto assumem um caráter ensaístico, na medida em que se concentram em polemizar algumas problemáticas relativas à dança na Educação Física Escolar. Neste sentido, muito mais do que um relato de experiência, trata-se aqui de um ensaio, isto é, de uma provocação, que reclama pela leitura crítica e reflexiva do próprio leitor. E para situar esse ensaio, é importante pontuar seu lugar de fala, onde a provocação levou-nos ao exercício da escrita.

Esse ensaio surgiu de uma experiência didática, envolvendo a disciplina de Ensino das Danças no contexto do Mestrado Profissional. Trata-se de uma disciplina eletiva realizada dentro do Programa de Mestrado Profissional em Educação Física em Rede Nacional (ProEF). A referida disciplina contou com a inscrição de vinte alunos regularmente matriculados no ProEF, dos respectivos núcleos da UNESP Rio Claro e UFSCar São Carlos, sendo todos eles professores de Educação Física Escolar, atuantes em redes municipais e estaduais de ensino. A carga horária total da disciplina foi de 30 horas/atividade, realizadas integralmente em modo presencial, no mês de janeiro de 2019.

Como primeira atividade da disciplina, os professores responsáveis conduziram um exercício de diálogo, na busca de informações sobre a prática profissional de cada um e, particularmente, a relação que tinham com a dança, como conteúdo de suas aulas. Na ocasião, perguntávamos: vocês trabalham com dança nas suas aulas na Educação Física Escolar? Quais são as facilidades e/ou dificuldades de se trabalhar com esse conteúdo?

Com a instauração desse espaço dialógico, que também serviu de avaliação diagnóstica, pretendeu-se engajar os conteúdos ministrados com as demandas da prática profissional, sem a qual a aprendizagem não ganha em sentido e significado para os professores cursistas na disciplina. Além disto, era necessário conhecer esses professores e seus respectivos contextos, para aproximar as proposições planejadas na disciplina com as suas expectativas, o que foi possível fazer através desta avaliação inicial. Em meio a esse exercício dialógico, muitas polêmicas apareceram, dando indícios de alguns desacertos instalados no encontro da dança com a Educação Física Escolar.

No rastro desses desacertos situamos as reflexões a seguir.

\section{DESACERTOS SEXISTAS ACERCA DA DANÇA NA ESCOLA}

Em tempos nos quais muitos parecem acreditar, mesmo que não assumam claramente, que "meninos devem vestir azul e meninas rosa", essa leitura encontra ecos com outras tantas que figuram nesta mesma linha discursiva - tal como aquela que dispara: "meninos jogam bola e meninas brincam de boneca", ou ainda, como aqueles preconceitos sexistas que afirmam: "dança é coisa de menina!" e que "menino que dança é gay!".

Assim, subliminarmente, acentuam-se atitudes que reforçam a edificação de uma realidade cada vez mais binária e sexista, que atinge em cheio as aulas de Educação Física Escolar, afetando a disposição e abertura de muitos professores em se trabalhar com o conteúdo dança no universo escolar.

Tal injunção já foi amplamente denunciada por autores que estudam a dança no contexto escolar. Marques (2012a), por exemplo, chama a atenção para o fato de que o preconceito, relativo ao gênero na dança escolar, é reflexo de uma leitura amplamente disseminada na sociedade que afeta não só os alunos como também seus núcleos familiares e sociais mais próximos.

Nota-se portanto que, no que tange às distinções de gênero, há uma dimensão estrutural enraizada no âmbito da cultura, que insiste em atrelar a dança ao gênero feminino, o que 
reforça processos de internalização e reprodução passiva de ideias e convenções relacionadas à essa temática, que são explicita e implicitamente disseminadas no contexto cultural, até serem naturalizadas pelo discurso da normalidade, que rege a delimitação e reprodução massiva dos convencionamentos sociais.

Andrade e Godoy (2018) reforçam essa ideia ao situarem que a instituição escolar está inserida em uma sociedade que apresenta uma certa ordem institucional historicamente situada. Essa ordem institucional é tão subliminar, que muitas vezes é reproduzida automaticamente, sem passar pelos crivos de uma atitude crítica e reflexiva. E o espaço escolar reflete amplamente essa injunção, ora reforçando-as, ora problematizando-as no cerne do trabalho pedagógico.

É no bojo dessa injunção, que se evidenciam discursos sexistas, maniqueístas e moralizantes, que em última análise, reforçam as leituras dicotômicas acerca daquilo que pode e do que não pode, do que é bom, ou mau, do que é certo ou errado. Nesta mesma direção, que demarca uma tendência instituinte em curso vertical e impositivo, reforçam-se também as distinções de gênero, em meio às quais, o peso dos convencionamentos ganha força, em detrimento da ação crítica e reflexiva.

$\mathrm{Na}$ leitura de Darido e Rangel (2005), essa situação influencia negativamente o trabalho pedagógico, reforçando práticas de exclusão e discriminação, além de resumir, de modo drástico, as experiências de integração entre meninos e meninas no espaço escolar, o que configura um obstáculo que dificulta o desenvolvimento mais profundo e aprimorado de determinados conteúdos, tais como a dança na escola.

É importante salientar que a dificuldade, neste sentido reiterado acima, não é intrínseca ao conteúdo dança, mas diz respeito às condições formais e concretas, em meio as quais o desenvolvimento desse conteúdo se opera. Condições essas que incidem diretamente sobre o potencial de ação instalado na relação de ensino, minando-o continuamente numa projeção que descaracteriza o sentido e as ações pedagógicas que poderiam, em vez disso, só ampliar o modo de ser e existir no mundo.

Frente à afirmação inconsequente de leituras sexistas acerca da dança na escola, é imperativo que o professor tome esse problema como ponto de pauta de suas aulas de dança, de modo a exercer um trabalho efetivamente educativo, sem o qual seu exercício pedagógico não ultrapassa os sexismos, tornando rarefeito e superficial o desenvolvimento da dança na Educação Física Escolar.

Nesta mesma direção, situada acima, convém lembrar - apoiado nas leituras de Marques (2012a; 2012b) e Gariba e Franzoni (2007) - que a dança só assume um papel verdadeiramente educativo quando é problematizada no seio da atividade social, em que, muito mais do que passos a serem reproduzidos e memorizados, o que se coloca em movimento é uma dimensão crítica e reflexiva amplamente engajada com a realidade em meio a qual as aulas de dança na escola acontecem. Como efeito dessa atitude de engajamento, reitera-se a vocação da dança no desenvolvimento expressivo e comunicativo dos alunos e, consequentemente, reforça-se a função e importância da dança na construção de um aluno mais criativo, autônomo, consciente, responsável e cidadão.

\section{DESMONTANDO O DISCURSO DA FALTA NA FORMAÇÃO INICIAL}

Outra discussão relatada por professores de Educação Física Escolar que trabalham com dança em suas aulas versa acerca de uma suposta carência na formação acadêmica inicial quanto à aquisição de conteúdos, habilidades e experiências ligadas ao trabalho com dança nas escolas. Mas até que ponto essa afirmação é factível? Em nossa leitura, essa discussão é muito polêmica e, em certa medida, bastante injusta! 
Para dar respaldo a essa reflexão, que busca por argumentos mais plausíveis que justifiquem a falta de trabalho com dança na Educação Física Escolar, voltamos nossa atenção para a grade curricular da formação inicial. Em uma análise preliminar e bastante geral acerca do currículo dos cursos de graduação em Educação Física, é possível notar que, embora haja certo destaque na alocação de disciplinas práticas, tais como a dança e as atividades rítmicas e expressivas, o fato é que, considerando a estrutura conteudista e bancária da formação, denunciada por Paulo Freire, em suas críticas sobre a educação hegemônica (FREIRE, 1975; 1979; 1996), essas disciplinas acabam ficando em segundo plano, relegadas ao título de vivências, que tendem a ser esquecidas, frente a outras demandas, de ordem disciplinar, teórica, objetiva e racional, exigidas para edificar o trabalho formativo em nível acadêmico, científico e profissional.

Essa afirmação encontra ecos na literatura. Para Imbernón (2010), a política acadêmica tende a ser pautada pelo conhecimento objetivo e disciplinar, que corre sobre os trilhos do conhecimento teórico-formal. Com isto, oportuniza-se a legitimação de saberes científicos que acabam por se consolidar no percurso formativo por força de afirmação e legítima autoridade dada pela ciência. Consequentemente, outras modalidades de saberes, tais como aqueles que advêm da prática são relativizados, até mesmo porque reclamam por constante validação e atualização, não só no processo da formação, mas também durante a prática profissional (VAILLANT; MARCELO, 2012).

Voltando à Dança, se relegamos nosso conhecimento apenas àquilo que o currículo inicial apresenta, de fato, o que se sabe pode parecer insuficiente para respaldar o trabalho do professor com dança nas escolas. Mas se essa lógica é factível, o mesmo deve valer para toda e qualquer outra prática, o que não é verdade! Basta lembrarmos, por exemplo, do futebol. Por que esse esporte é tão presente nas aulas de Educação Física Escolar? Será que é porque a disciplina de futebol, na formação inicial, foi amplamente abrangente e satisfatória?

Independente se a resposta à última questão for sim, ou não, o fato é que a cultura popular, impulsionada pela especulação midiática, alimenta uma relação muito intensa com o futebol no Brasil, consequentemente, muito sobre o futebol é incorporado quase que de modo subliminar, o que, de certo modo, ajuda a entender porque essa prática está tão presente no imaginário dos alunos e que, portanto, figura como uma prática quase obrigatória nas aulas de Educação Física Escolar.

Será que essa mesma situação se aplica ao ensino das Danças na Escola? Certamente não! O que é curioso, como já denunciado por Marques (2012a), é que somos um país dançante, com uma cultura rítmica e expressiva internacionalmente reconhecida, graças à riqueza de nossas manifestações regionais, populares e folclóricas. Não obstante, o cenário educacional envolvendo dança parece não ter a mesma visibilidade, tampouco gozar do mesmo prestígio quando posto em pauta nas aulas.

\section{O MITO DA FALTA DE INTIMIDADE COM A DANÇA}

Outro desacerto polêmico comumente relatado por professores de Educação Física é a falta de prática e proximidade desses professores com a dança. E para consolidar o peso e amplo cabimento deste mito, reiteram frases do tipo: "não pratico dança, portanto, não me sinto à vontade para ministrá-la!".

No caso da disciplina de Ensino das Danças, no Mestrado Profissional, foi possível observar que atrelado a esse mito se engajou também um desejo de buscar nesta disciplina, vivências em danças que pudessem ser conduzidas, ou reproduzidas, pelos professores no contexto de suas atividades de ensino nas escolas. Tal preocupação nos levou a pensar na seguinte questão: o que é dança para esses professores? 
Ao se preocupar com a aquisição de princípios técnicos específicos, por meio das quais fosse possível vislumbrar a inclusão da dança nas suas aulas, os professores revelaram certo entendimento intimamente ligado à noção de modalidades de dança, tais como ballet, jazz, danças de salão, ou outros estilos historicamente constituídos. É claro que o ensino de modalidades de dança também pode integrar a prática da dança na escola, como já observado por Marques em seus estudos (2012a; 2012b), mas resumir o ensino da dança escolar à transmissão e reprodução dessas técnicas é uma opção bastante limitada e limitante, que não explora amplamente toda a potencialidade educacional da dança. Foi pensando em desconstruir esse mito, que a disciplina de Ensino das Danças buscou respaldo na Dança Criativa, à luz dos estudos Labanianos (LABAN, 1990; 1978).

\section{AMPLIANDO A NOÇÃO DE DANÇA DOS PROFESSORES}

Segundo a leitura de Marques (2012a, 2012b), Dança Criativa é também chamada de Expressão Corporal, ou Dança Expressiva e, quando pautada a partir do referencial labaniano pode ser chamada também de Dança Laban ou Método Laban. Para além das especificidades que cada nomenclatura pode levar, de modo geral, a Dança Criativa possibilita que os alunos criem suas próprias danças com seus corpos e emoções, além de permitir e incentivar os alunos a experimentar, explorar e expandir a própria expressividade. Para tanto, as aulas de Dança Criativa se desenvolvem como espaços laboratoriais de pesquisa e exploração das possibilidades de movimento.

Convém salientar que a noção de pesquisa de movimentos, introduzida no contexto da Dança Criativa, trouxe a dança para perto do contexto da Educação Física, chamando a atenção dos pesquisadores dessa área de estudo quanto à importância dessa prática no desenvolvimento psicomotor e, portanto, como conteúdo fundamental na Educação Infantil (MARQUES, 2012a; 2012b).

O problema que a Dança Criativa apresenta para o professor atuante na Educação Física Escolar é que demanda a necessidade de se deslocar a noção de aula, de modo a veicular nelas práticas lúdicas de pesquisa corporal, em detrimento das práticas de simples assimilação e reprodução de passos coreografados. E é justamente aí, neste deslocamento, que a situação se complica, haja vista que a realidade educacional nem sempre contribui para a instalação desta outra disposição educativa.

Strazzacappa (2001) nos ajuda a refletir sobre essa injunção. De acordo com essa pesquisadora, o modo como o sistema escolar é organizado contribui para a imobilização dos corpos, pois dá preferência ao mecanismo de reprodução e assimilação de códigos corporais já cristalizados, em detrimento do trabalho criativo de pesquisa e exploração das possibilidades de transgressão dos movimentos corporais. Desta forma, o sistema educativo, como um todo, vai anestesiando a expressividade dos alunos, reduzindo-a drasticamente até a quase imobilização. Frente a essa realidade, que tende a fazer da educação uma linha de produção quase industrial, os preceitos Labanianos figuram como estratégias de resistência, que afirmam o potencial criativo e expressivo dos alunos.

Não obstante, a prática da Dança Criativa, durante o curso da disciplina de Ensino das Danças, disparou desconfianças (aos olhos) daqueles que insistiam em pensar a dança com os "olhos" das modalidades de dança historicamente constituídas. Isto aconteceu porque, ao experimentar os princípios da Dança Criativa, lhes pareceu trabalhar muito mais com práticas rítmicas do que propriamente com Dança ${ }^{3}$.

\footnotetext{
${ }^{3}$ A exploração dos princípios da Dança Criativa passa pela pesquisa corporal apoiada em temas, tais como: centro de gravidade, planos e níveis de movimentação, exploração da kinesfera (espaço pessoal), expressividade e suas relações com o peso, o espaço, o tempo e a fluência, dança coral, dentre outros (MARQUES 2012a).
} 
E de fato essa sensação tem certo fundamento, principalmente quando o conteúdo dança se confunde com modalidades de dança. O problema deste entendimento é deixar de considerar aquilo que vaza à ordem protocolar, alertando-nos sobre certa indissociabilidade entre dança, ritmo, criatividade e expressão corporal. É preciso considerar que, em certa medida, a ordem protocolar e regulamentar, que organiza os conteúdos de ensino, muitas vezes, pode obliterar, ou dificultar a expressão dos saberes que advém da prática, ao definir o que pode do que não pode, o que é e o que não é dança, em detrimento de uma atitude experimental, lúdica e criativa insistentemente minimizada, quando se sistematizam drasticamente os conteúdos.

Por mais que a tendência à categorização das práticas tenha sua função e sentido, principalmente quando a ideia é sistematizar o quadro curricular e organizar conteúdos específicos da Educação Física, o fato é que, quando se trabalha com dança, se experimenta a possibilidade de dissolução destas categorias, o que parece algo inimaginável para grande parte dos professores que não têm proximidade com a dança. Essa desconstrução permite encontrar dança, onde o olhar viciado nas categorias não costuma encontrar, tal como no futebol, por exemplo. Mas será que os fundamentos do futebol não podem oferecer também estímulos para práticas de criação em dança? Será que uma condução de bola, por exemplo (um dos fundamentos deste desporto), não pode servir como ponto de partida para pensar na exploração de diferentes outras formas de condução? A questão aqui é focar, mesmo que minimamente, naquela disposição laboratorial de aula, que prefere apostar no lúdico, no experimental e inventivo, em detrimento de princípios de ação pressupostos, afirmados durante a intervenção pedagógica.

Neste sentido, o fundamento da condução de bola, tal como exemplificado acima, passa a funcionar como um estímulo para a exploração de outros modos de condução, nos quais se pesquisa o corpo em diferentes planos, níveis, ritmos, direções e sentidos. São essas demandas lúdicas e criativas que são aqui evidenciadas, não para demarcar as distinções entre dança e futebol, mas, antes, possibilitar a experimentação da dimensão lúdica, por meio da qual tangenciamos a dança - pelo menos aquela que diz respeito à sua essência criativa e inventiva, que aponta sempre para uma prospecção, isto é, uma percepção em devir, aberta, de acordo com as demandas em curso na aula.

\section{UMA APOSTA}

Como já indicado anteriormente, as modalidades de dança, tais como o ballet, o jazz, ou qualquer outra técnica historicamente constituída, também têm seu papel e função no âmbito educacional. O que não se pode fazer, tal como afirmado por Marques (2012a; 2012b) é resumir o papel educativo da Dança à transmissão e reprodução dessas técnicas no contexto escolar.

Tendo em vista essas prerrogativas, o importante, enquanto educadores, é que possamos organizar os diferentes conteúdos acerca da dança, de acordo com a evolução do trabalho educacional, que deve estar intimamente atrelado ao desenvolvimento humano (LABAN, 1990). Nas fases iniciais de ensino, por exemplo, a Dança Criativa se encaixa perfeitamente, pois oportuniza um espaço interessante de pesquisa e exploração das possibilidades de movimento da criança e que certamente irá contribuir para qualificar seu desenvolvimento integral, dando respaldo para aprendizagens cada vez mais complexas.

Com a chegada da adolescência e juventude, talvez seja interessante apostar em outras práticas de Dança, tais como aquelas advindas das diferentes modalidades historicamente constituídas. Mas em quais dessas modalidades deve-se apostar? 
Primeiramente, é importante reconhecer a impossibilidade de se afirmar uma resposta cabal (perfeita, única ou definitiva) a essa questão. Cada caso é um caso e deve levar em conta a realidade concreta de cada prática e também as experiências e saberes dos educandos (FREIRE, 1996). Assim, considerando que todos os alunos matriculados na disciplina de Ensino das Danças, no contexto do Mestrado Profissional, ministravam aulas em escolas públicas estaduais e municipais de ensino e, levando em consideração a ligação desses universos escolares com a cultura urbana e popular das periferias urbanas, optamos por apostar em uma outra prática que estivesse mais próxima deste contexto. Foi então, que pensamos na inserção da dança da cultura Hip-hop como um dos conteúdos desenvolvidos dentro da referida disciplina.

É inegável a influência desta cultura nas manifestações urbanas da atualidade, seja através no Funk, das danças sociais ${ }^{4}$, das manifestações regionais, como a capoeira e o frevo, ou ainda em manifestações recentes, como no K-pop ${ }^{5}$, o Hip-hop tem conquistado espaços de expressão que invadem a cidade, afetando os modos de ser e agir da juventude (ALVES; DIAS, 2004). Ora, se essa expressão artística e cultural consegue afetar os modos de existir da juventude urbana, tal como afirmado por Alves (2001) e Alves e Dias (2004) em seus estudos, ela invade também o espaço escolar e modula, de alguma forma, a expressividade dos alunos. Tendo em vista essas demandas: por que não as aproveitar nas aulas de dança na Educação Física Escolar?

Apostar na possibilidade de inserção da dança Hip-hop aponta, ao menos, para uma disposição do professor em dialogar com conteúdos significativos para os alunos, haja vista que trata-se de uma cultura que, de uma forma ou de outra, afeta os modos de ser e estar dos alunos no universo urbano e que, portanto, não deixa de estar presente no contexto das escolas.

A seguir, apresentamos alguns questionamentos-chave, definidos a partir das dimensões do conhecimento (DARIDO; SOUZA JÚNIOR, 2007), que podem ajudar na composição de aulas sobre a dança da cultura Hip-hop. A intenção, aqui, não é esmiuçar detalhadamente como se daria o desenvolvimento destes conteúdos nas aulas, mas apontar direcionamentos que oportunizem um trabalho pedagógico pautado pelo exercício dialógico mais horizontal entre professor e alunos, que viabilize a intensa troca de experiências e conhecimentos entre esses agentes educacionais sobre esse conteúdo em questão:

- Quais são os estilos da dança Hip-hop? Em que se diferem? Que qualidades de movimento lhes são particulares? Em quais espaços essas danças são geralmente dançadas e sob quais condições? Essas questões orientam o desenvolvimento da dimensão procedimental dos conteúdos, movendo professor e alunos ao trabalho de pesquisa, na busca de respostas que giram em torno de um certo "saber-fazer" impresso no âmbito da cultura Hip-hop.

- De onde vem o Hip-hop? Qual a história desta manifestação? Qual sua ligação com o Funk, as danças sociais, as manifestações regionais e com o K-Pop? Essas questões orientam o desenvolvimento da dimensão conceitual dos conteúdos, movendo professor e

\footnotetext{
${ }^{4}$ A expressão "danças sociais" é bastante generalista e pode ser aplicada a vários contextos, mas considerando o contexto das manifestações de rua, é frequente entender as danças sociais como a forma social de se dançar o Hip-hop. O que difere a dança da cultura Hip-hop das danças sociais é que enquanto aquele tem um viés performático, as danças sociais valorizam a diversão, o entretenimento. São realizadas, geralmente, em grupos e trabalham sequências de passos simples, com pequenas progressões e deslocamentos, que se repetem ciclicamente, com isso, o participante pode entrar e sair da dança a qualquer momento (ALVES, 2001; ALVES; DIAS, 2004).

${ }^{5}$ K-Pop é um estilo musical caracterizado pela grande variedade de elementos audiovisuais. Surgiu na Coréia do Sul, em meados da década de 1990 e devido à sua natureza híbrida, que integra, dentre outras culturas, elementos da cultura Hip-hop, se espalhou pelo mundo inteiro com ampla adesão de jovens e adolescentes vidrados nos clipes musicais veiculados pela internet.
} 
alunos ao trabalho de pesquisa, na busca de respostas que giram em torno de um certo "saberestar" em cena na cultura Hip-hop.

- Deve-se trabalhar com o Funk nas escolas? Por que no Funk, no Rap (a música da cultura Hip-hop) e em outras manifestações ligadas a essa cultura, se encontra com tanta frequência temáticas como a violência, a criminalidade, o sexo, o machismo e a misoginia? Essas questões orientam o desenvolvimento da dimensão atitudinal dos conteúdos, movendo professor e alunos ao trabalho de pesquisa, na busca de respostas que giram em torno de um certo "saber-ser" expresso no âmbito da cultura Hip-hop.

Observe que, com esse nível de problematização das dimensões de conteúdos concernentes à dança da cultura Hip-hop, entra em cena uma estratégia de ensino da dança mais focada no protagonismo do aluno e na mobilização daquilo que ele próprio quer pesquisar e aprender.

Neste sentido, notam-se aproximações com as chamadas metodologias ativas, nas quais a ideia não é transmitir conhecimentos, mas disparar um processo de pesquisa, que move um intenso trabalho laboratorial de composição dos conhecimentos viabilizados pelos próprios alunos, sob a orientação do professor. E o que é importante observar desse trabalho laboratorial é que ele não se encontra na linearidade pré-estabelecida do ensino, isto é, nos procedimentos pressupostos, mas sim nas intensidades e sentidos só desdobrados na experiência concreta das aprendizagens, em que professor e alunos, juntos, trilham caminhos singulares e construtivistas, muito mais focados na prospecção do aprender, do que na firmação protocolar do ensinar (BERBEL, 2011).

$\mathrm{Na}$ perspectiva das metodologias ativas para o ensino da dança, a mobilização das aprendizagens independe se o professor tem ou não experiência prévia com o Hip-hop, isso porque, o foco não está na habilidade pré-estabelecida do ensinar - tanto no que se refere à sua dimensão procedimental, quanto conceitual e atitudinal - mas sim na prospecção de uma aprendizagem, que está sempre por vir no encontro lúdico, experimental e interativo estabelecido entre os agentes envolvidos no processo educativo.

Nestes termos, o que importa, portanto, é a disposição ao trabalho inventivo, constituído de modo colaborativo e co-autoral entre alunos, e entre professor e alunos, na sala de aula. Essa disposição, de certo modo, corrobora com os princípios da Dança Criativa, em que as aulas não são transmitidas, mas experimentadas sempre e a cada vez, de modo lúdico e inventivo, nos laboratórios de pesquisa corporal.

Em diálogo direto com as metodologias ativas, podemos situar também a noção de práticas corporais, compreendendo-a como operador teórico-conceitual interessante para oportunizar uma organização dos conhecimentos relativos à dança na Educação Física Escolar muito mais afeita ao protagonismo dos alunos durante as aulas ${ }^{6}$. Neste sentido, veiculado pela noção de práticas corporais, o que mais importa é a afirmação de uma atitude curiosa de pesquisa que mobiliza amplamente a ação educativa, demovendo o aluno da situação de mera passividade, em que lhe cabe apenar assimilar conteúdos prévios, impostos pelo professor.

Sob esse enfoque, reiterado à luz das práticas corporais, somos convocados, enquanto professores, a considerar amplamente os anseios e motivações dos alunos, o que nos coloca o desafio de conciliar também outros imperativos educacionais, tais como aqueles que vão dar visibilidade ao processo coeducativo, cooperativo e mais sensível à formação do cidadão crítico, emancipado e autônomo.

\footnotetext{
${ }^{6}$ De acordo com González, Darido e Oliveira (2014), organizar o conhecimento à luz das práticas corporais implica em mobilizar uma prática de pesquisa acerca daquilo que se pretende aprender, colocando em movimento os princípios da coeducação, da cooperação, da autonomia, da emancipação, dentre outros, que transitam na relação educativa, quando se permite a instalação de uma relação mais horizontalizada entre professor e alunos, que oportunize mútuas aprendizagens sempre em via de mão dupla, em que todos aprendem, inclusive o professor.
} 


\section{CONSIDERAÇÕES FINAIS}

A reflexão acerca dos desacertos da dança no contexto da Educação Física Escolar, nos faz lembrar que o trabalho com dança nem sempre é uma proposição fácil de ser cumprida durante as aulas de Educação Física, pois o peso desses desacertos, muitas vezes, parece ser maior do que motivação em superá-los. E essa injunção leva, não raras vezes, ao apagamento do conteúdo dança dentro da grade curricular, ou ainda, à reafirmação de certas práticas, que acabam resumindo o trabalho com dança a ocasiões festivas e folclóricas, que mais entretêm do que propriamente educam, ao levar pais, alunos e professores à falsa impressão de que a dança só parece ter cabimento e função para prover estas ocasiões.

Apesar disso, é preciso apostar! Uma aposta que não se faz sem antes ampliar o entendimento dos professores acerca do que é dança. Neste sentido, a disciplina de Ensino das Danças foi buscar respaldo na Dança Criativa e nos estudos Labanianos, assim, foi possível colocar no centro do processo educativo a atitude da pesquisa corporal, sem a qual não emerge a dança em suas facetas múltiplas e plurais, que vazam a todo e qualquer esforço de enquadrá-la nesta ou naquela modalidade específica.

Desta centralidade da prática de pesquisa corporal, cabe ao professor considerar amplamente as demandas que advêm do âmbito da cultura, para que sejam evidenciados também os anseios e expectativas dos alunos no desenvolvimento da dança no contexto escolar.

É no bojo desse processo - que deve ser sempre refletido e situado, e que, portanto, sempre considera as condições concretas de intervenção - que apostamos na dança da cultura Hip-hop, de modo a se alinhar com algumas motivações da juventude urbana. Mas, vale lembrar que se tratou apenas de uma aposta, dentre outras tantas possíveis!

O que não se pode perder de vista, jamais, é o trabalho da reflexão situada ${ }^{7}$, sem o qual não se dá efetividade, singularidade e validade à aposta assumida pelo professor em sua ação educativa envolvendo dança na escola.

\section{REFERÊNCIAS}

ALVES, F. S. Dança de rua: corpos e sentidos em movimento na cidade. 2001. 148 f. Trabalho de Conclusão de Curso (Graduação em Educação Física) - Instituto de Biociências, Universidade Estadual Paulista, Rio Claro, 2001.

ALVES, F. S.; DIAS, R. A dança break: corpos e sentidos em movimento no hip-hop. Motriz, v.10, n.1, p.0107, jan./abr. 2004.

ANDRADE, C. R.; GODOY, K. M. A. Dança com crianças: propostas, ensino e possiblidades. Curitiba: Appris, 2018.

BERBEL, N. A. N. As metodologias ativas e a promoção da autonomia de estudantes. Ciências Sociais e Humanas, v. 32, n. 1, p. 25-40, jan./jun. 2011.

DARIDO, S. C.; RANGEL, I. C. A. Educação física na escola: implicações para a prática pedagógica. Rio de Janeiro: Guanabara Koogan, 2005.

\footnotetext{
${ }^{7}$ Na leitura de Rangel et al. (2005), a ação reflexiva oportuniza ao professor que reflita "[...] o tempo todo sobre suas ações, construindo e comparando novas estratégias de ação, novas fórmulas de pesquisa, novas teorias e categorias de compreensão, novos modos de enfrentar e definir os problemas" (p. 105).
} 
Flávio Soares Alves; Yara Aparecida Couto

DARIDO, S. C.; SOUZA-JÚNIOR, O. M. Para ensinar educação física: possibilidades de intervenção na escola. Campinas: Papirus, 2007.

FREIRE, P. Pedagogia da autonomia: saberes necessários à prática educativa. São Paulo: Paz e Terra, 1996.

FREIRE, P. Educação e mudança. Rio de Janeiro: Paz e Terra, 1979.

FREIRE, P. Educação como prática da liberdade. Rio de Janeiro: Paz e Terra. 1975.

GARIBA, C. M. S.; FRANZONI, A. Dança escolar: uma possibilidade na educação física. Revista Movimento, v. 13, n. 2, p. 155-171, 2007.

GONZÁLEZ, F. J.; DARIDO, S. C.; OLIVEIRA, A. A. B. Ginástica, dança e atividades circenses. Maringá: Eduem, 2014. (Coleção Práticas Corporais e a Organização do Conhecimento).

IMBERNÓN, F. formação docente e profissional: formar-se para a mudança e a incerteza. São Paulo: Cortez, 2010.

LABAN, R. Dança educativa moderna. São Paulo: Ícone, 1990.

LABAN, R. Domínio do movimento. São Paulo: Summus, 1978.

MARQUES, I. Dançando na escola. São Paulo: Cortez, 2012a.

MARQUES, I. Interações: crianças, dança e escola. São Paulo: Blucher, 2012b.

RANGEL, I. C. A.; SANCHES NETO, L.; DARIDO, S. C.; GASPARI, T. C.; GALVÃO, Z. O ensino reflexivo como perspectiva metodológica. In: DARIDO, S. C.; RANGEL, I. C. A. Educação física na escola: implicações para a prática pedagógica. Rio de Janeiro: Guanabara Koogan, 2005. p. 103-121. (Coleção Educação Física no Ensino Superior).

STRAZZACAPPA, M. A educação e a fábrica de corpos: a dança na escola. Cadernos CEDES, v. 21, n. 53, p. 69-83, abr. 2001.

VAILLANT, D.; MARCELO, C. Ensinando a ensinar: as quatro etapas de uma aprendizagem. Curitiba: Editora UTFPR, 2012.

Recebido em: 01 dez. 2020.

Aprovado em: 17 dez. 2020. 